\title{
NOTAS SOBRE IDENTIDAD Y DIVERSIDAD CULTURAL
}

\author{
Alfredo SALDAÑA \\ Universidad de Zaragoza
}

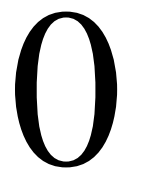

¿En qué sentidos las prácticas culturales responden a necesidades, intereses y deseos individuales o colectivos?, ¿en qué medida esas prácticas nos interpelan y conforman, manipulándonos en ocasiones, coartando nuestra libertad y actuando como estructuras ideológicas más o menos represivas?, ¿hasta qué punto la cultura es un medio de proyección o de opresión del ser humano?, ¿es la cultura global resultado de la suma de culturas parciales o de procesos constantes de transculturación?, ¿de qué manera el saber y lo imaginario están entrelazados?, son preguntas que afectan a la línea de flotación de muchas de nuestras sociedades, en las que el desarrollo de la tecnología digital, reticular y telemática ha modificado unos hábitos de pensamiento en los que la identidad, la historia y la cultura son ya, necesariamente, categorías que hay que volver a formular, y ello sobre unas coordenadas inéditas de tiempo y espacio.

1. Desde hace ya unos cuantos años la realidad social y cultural a la que nos enfrentamos -sobre todo en las grandes metrópolis- es sensiblemente diferente a la que vivieron las generaciones anteriores. Por eso mismo, porque la realidad es otra, es urgente elaborar miradas, lenguajes y modelos de análisis e interpretación que den cuenta de esos escenarios y, de paso, aceptar que el fondo de la cuestión radica en evitar el etnocentrismo y el dogmatismo excluyentes, en la posibilidad de contemplar y nombrar el mundo de otra manera, en la coyuntura de vernos representados a través de la mirada del otro y en el trato que decidamos establecer no tanto con los parecidos a nosotros sino con aquellos otros compañeros de viaje que son diferentes a nosotros, y para esos otros nosotros somos los otros (y toda esta argumentación debiera entenderse a partir de la dificultad de delimitar con precisión el alcance de ese nosotros).

El tema entonces viene dado por la relación que seamos capaces de mantener con la realidad ajena y, en ella, con el otro, ese que nuestro imaginario convencionalmente etiqueta como forastero, ilegal, deportado, sin papeles, extranjero, desplazado, inmigrante, refugiado... Y habrá que reconocer que ese otro representa el negativo de nuestra propia identidad, la cara oculta, la voz callada, silenciada 
y temida que dejamos a un lado, escondida en nuestro interior. Los constantes flujos de personas de unos lugares a otros del planeta generan nuevas expresiones culturales, y ese hecho muestra que la identidad cultural está en constante formación; al mismo tiempo, se producen movimientos de lenguas, costumbres, ideologías y creencias que afectan a los denominados procesos de glocalización y que ponen en juego, entre otras muchas cosas, tanto ese difícil equilibrio en el que deben coexistir lo local y lo global como el estatuto de la identidad, esa categoría constituida por elementos culturales e históricos y no genéticos y trascendentales, como en más de una ocasión se ha querido mostrar y en nombre de la que tantas barbaridades se han cometido (Saldaña, 2013).

En estas circunstancias, se trataría de iniciar sobre ese escenario movedizo no un discurso sagrado, solemne, oracular o profético sino un diálogo civil, social e histórico a partir del reconocimiento de que las voces implicadas en esa conversación son diferentes y de que ninguna de ellas es por sí misma -sin las otras- la propietaria de la norma, la ley, la razón o la verdad; hablar desde el convencimiento de que los sentidos de los términos empleados no están fijados de antemano, decir desdiciéndonos, desautorizándonos, contradiciéndonos si fuese preciso. Y con ese aleteo que nos permita levantar algo el vuelo y ganar perspectiva confrontar diferentes modelos culturales, es decir, distintas opciones vitales. Imaginar, por ejemplo, manifestaciones revolucionarias inéditas en un momento en que la fobia a las revoluciones, la legitimación del conservadurismo y la doxa que defiende que no hay vida posible más allá de la democracia liberal son planteamientos dominantes que se extienden como una pandemia que ahoga la posibilidad de cualquier pensamiento crítico. Imaginar acaso otro mundo donde la palabra deje de actuar al dictado de un pensamiento limitado y constreñido por cualquier ideología y recobre ese aliento desestabilizador, rebelde, insurreccional y subversivo con el que recrear la existencia.

2. La cultura constituye un territorio poroso del saber no siempre delimitable con facilidad, permeable, polisémico, inestable, movedizo, que indica, como sugiere la etimología, la confluencia de vías, pasajes y senderos superpuestos y no tanto la localización de un espacio preciso, un territorio sobre el que se han librado continuas batallas a lo largo de la historia y en el que la razón y la identidad propias han sido utilizadas a menudo como armas de aniquilación del otro, hasta el punto de que podría afirmarse que, en nombre de la cultura, se han alcanzado tantos logros de civilización como atrocidades se han cometido. Y todo esto ha sido así porque, además de unas implicaciones gnoseológicas, la cultura se ha desarrollado como sistemas de valores, ideas y creencias que las sociedades han adoptado en forma de modelos de comportamiento. La modernidad ilustrada vio en la cultura un rasgo de civilización e introdujo la noción de tiempo lineal, evolutivo e irreversible, de tal modo que quedó asociada a la idea de progreso. Valoramos así en parte el progreso de una sociedad por su potencial cultural y juzgamos ese potencial por el progreso que es capaz de reportar a esa misma sociedad. Sin embargo, a lo largo de la historia la cultura ha sido un campo abonado de luchas, dispuesto para la 
confrontación de intereses, adecuado para la representación e imposición ideológicas de diferentes modelos de mundo.

La cultura está en condiciones de abrir las heridas por las que se desangra parte del tejido social $\mathrm{y}$, al mostrar esas grietas, puede ser un buen exponente como lugar de conflicto, resistencia y negociación en sociedades como las que hoy se dan en Occidente, fracturadas por divisiones de renta, género, clase, religión y raza. Cultura, pensamiento y lenguaje se han entrecruzado a lo largo de la historia en el trabajo de escritores - poetas, narradores, filósofos, etc.- que no renuncian a contemplar el mundo con una mirada crítica capaz de nombrar el mundo de otra manera; cabe entonces la posibilidad de pensar que hay un mundo inexplorado más allá del mundo que conocemos a través del lenguaje que utilizamos habitualmente. Así, defender la creación cultural como un acto de civilización frente a la barbarie (aunque esta sea muchas veces un estado generado por sujetos no precisamente incultos), optar por la reflexión y no por la irracionalidad, dar una oportunidad a la horizontalidad del diálogo frente a la verticalidad de los discursos impuestos desde el poder, sean los que sean, son acciones necesarias en un mundo como este, sometido por la dictadura de los denominados mercados financieros y condenado a representarse a sí mismo en esa sociedad del espectáculo debordiana que ha decidido dar la espalda a lo real.

La historia nos ha enseñado que un escenario como la cultura, tan relevante en la configuración de cualquier sociedad, tiende a funcionar como un dispositivo de poder real, un mecanismo para provocar tanto la activación como la esterilización del pensamiento. En estas condiciones, una política cultural sostenida con recursos públicos no debería reducirse al entretenimiento, la representación de lo superfluo o la ocupación de un tiempo de ocio, ni plegarse a los intereses del mercado (que ve en la cultura no un derecho sino una mercancía que se puede comprar y vender); esa política cultural tendría que garantizar el derecho de los ciudadanos al acceso y a la producción culturales y asegurar la intervención de esos mismos ciudadanos como sujetos sociales y políticos -en la Política, Aristóteles

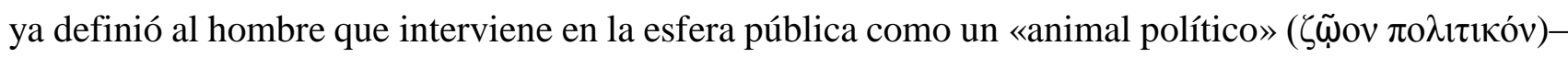
en la distribución de los presupuestos públicos y en la elaboración de las programaciones culturales. Así, entendida como un derecho, la cultura puede convertirse en un lugar radical de oposición a este neoliberalismo voraz y sanguinario que no ceja en la supresión de las conquistas públicas y los avances sociales, transformándolos en productos dotados de un valor económico de cambio, es decir, en prerrogativas de clase. Y como quienes detentan el poder económico no ignoran que estas cosas funcionan así, con gran interés se afanan por gestionar la industria cultural a sabiendas de que quien fiscaliza la cultura controla gran parte del pensamiento crítico. Obligada constantemente a autoaniquilarse en su permanente búsqueda de la unidad perdida (Debord, 2000), algunos objetivos de la cultura deberían consistir en velar por lo desaparecido y mantener viva la llama de la crítica. Solo en esas circunstancias -en las que una sociedad está dispuesta a explorar y ahondar en sus propias contradicciones y tensiones internas, poniendo en tela de juicio su propio canon cultural- puede la cultura ser exponente de una actividad popular y democrática organizada como un contrapoder social 
efectivo, funcionar como un elemento de reflexión para distinguir críticamente entre lo real y lo irreal y dar sentido a una visión progresista y emancipadora de la historia. Pero ¿cómo articular ese proceso de construcción y emancipación cultural en un momento en que, con demasiada frecuencia, la cultura ha dejado de ser índice de progreso y garantía de dignidad humana?

3. Cultura es un concepto polisémico y ambivalente, ambivalencia que, en algunos casos, ha permitido que lo cultural pueda entenderse como un mecanismo de neutralización de conflictos entre colectivos sociales en discordia y, al mismo tiempo, como expresión de las diferencias identitarias de cada uno de esos colectivos, es decir, como un dispositivo de cohesión e integración de un nuevo sistema social, trabajo desarrollado únicamente a riesgo de presentarse también como artefacto de desestabilización y desorden. Por otra parte, es sabido que todo sistema cultural se establece sobre la base de distintos modelos y criterios de selección que constantemente se están poniendo en tela de juicio. En este sentido, el lugar de la cultura es el lugar de la crítica, una crítica que puede operar como medio de cohesión y homogeneización o como venero de ruptura y desestabilización.

La posmodernidad no ha cesado de reinterpretar sus relaciones con la cultura: anulada la distinción entre alta cultura o cultura de élite y cultura popular y/o cultura de masas, hoy se muestra como una categoría deslocalizada, heterotópica, condenada a errar permanentemente a la búsqueda de referentes y señas de identidad, una categoría, en todo caso, que tiende a verse como un bien comercial o de consumo cuya vida responde a los latidos de la industria y el mercado, que se dosifica en porciones envasadas al vacío y adaptadas a las necesidades e intereses de cada consumidor, algo que reposa siempre sobre una sutil relación ambivalente entre la privación y el deseo; como señala Michel Bounan (2007), el sistema mercantil se basa en un juego de correspondencias entre la miseria y la opulencia, la frustración y la satisfacción de las necesidades: «La miseria de la necesidad es, sin duda, la materia prima del sistema mercantil, y quienes lo gestionan deben roer siempre algo más de lo que resta de libertad humana para imponer su monopolio sobre la satisfacción de las necesidades vitales» (Bounan, 2007: 162). En este contexto heterotópico, tremendamente injusto y alienante, cultura e identidad son conceptos entrelazados y la conciencia cultural desempeña una función cada vez más significativa en los procesos de cohesión social.

Ahora bien, en sociedades - como muchas de las occidentales- en las que la cultura ha perdido buena parte de su componente crítico asistimos a procesos de desemantización cultural en los que, paradójicamente, la cultura parece contaminarlo todo (se habla de «cultura del ocio», sintagma que presenta la cultura como algo acrítico, secundario y vinculado al tiempo del descanso o de las vacaciones, «cultura McDonald», «cultura del fútbol», «nueva cultura del agua», «cultura gastronómica», «cultura corporativa», «cultura instituciona», «cultura administrativa», «cultura de empresa», «cultura democrática», «cultura física», etc.) y casi siempre promoviendo valores y modelos de vida occidentales. Todo se reviste de una pátina cultural y, así, hasta la más nimia experiencia vital adquiere una dimensión cultural extraordinaria. De este modo, ante una actividad cultural 
extraordinariamente acomodaticia, ligada al ocio y vaciada de todo elemento rebelde y subversivo, concebida más como bálsamo que como generador de tensiones, la idea de interpelación (acuñada por Louis Althuser y tan necesaria en estos tiempos de penuria crítica) parece haberse desdibujado en el horizonte epistemológico de estas prácticas significativas. La cultura ya no interpela, no inquieta, no incordia con sus preguntas ahora ya casi nunca molestas o impertinentes; se limita a consolarnos, entretenernos o regalarnos el oído o la vista con aquello que nos resulta placentero oír o ver. En este sentido, los estudios culturales podrían preguntarse acerca del proceso según el cual la práctica cultural ha perdido su componente rebelde, crítico y utópico y se ha transformado en un mecanismo más de control y manipulación social.

Ahí, en ese plano donde se entrecruzan lo singular y lo colectivo -los intereses propios y los ajenos- surge el conflicto de la identidad (un motivo central en algunas líneas investigadoras de los estudios culturales, sobre todo en aquellas más relacionadas con la crítica poscolonial y las cuestiones de género), el trance en el que la propia identidad -si no acaba siendo borrada- emerge como resultado de una negociación con otras identidades (Saldaña, 2011); ahí también -donde el yo aparece desprotegido de toda certeza inamovible- debería desarrollarse el espíritu crítico y concederse el mismo estatuto -el mismo grado de jerarquía- a las diferentes sensibilidades.

Las continuas oleadas de inmigrantes que, empujados por la desesperación y el hambre, están llegando desde hace décadas a este multiestado paneuropeo con la intención no de suplicar algo de caridad sino de ganarse la vida con su esfuerzo y su trabajo (de los que tanto de beneficia el capital) deberían ser un buen motivo para que los europeos reflexionaran sobre el escenario en el que quieren vivir, sobre la pertinencia de luchar por un mundo en el que quepan diferentes modelos culturales y de convivencia, se reconozcan distintas idiosincrasias y se escuchen diversas lenguas. Sin embargo, en tiempos de escasez y de penuria, lo fácil es encontrar en el otro el ogro que amenaza con su sola presencia nuestro modelo de vida. Ahora bien, ¿cómo establecer los rasgos de una identidad europea que se fundamenta en su particular y compleja diversidad? Ahí se encuentra uno de los retos que en Europa debería afrontarse, la construcción de un espacio plural que a partir de la autocrítica sea capaz no solo de convertirse en modelo de coexistencia y colaboración entre las diferentes identidades sino también de mostrarse receptivo y permeable frente a las influencias ajenas, y todo ello sin duda debería redundar en la riqueza cultural de ese mismo escenario, una riqueza directamente proporcional a la diversidad lingüística, religiosa, artística y de comunidades característica de esta zona del planeta. En el caso europeo, la potencia de muchas de sus tradiciones regionales y locales -unida al pasado imperialista de algunos de sus Estados- ha restado coherencia y cohesión a una identidad europea que tendrá que forjarse sobre el reconocimiento y la aceptación de las diferentes identidades que la conforman, sobre la superación de la idea maniquea que encuentra perfectamente localizados el bien y el mal, lo aprovechable y lo desechable, a ambos lados de una frontera que separa el espacio que ocupamos nosotros del espacio que ocupan los otros. Y ese espacio conjunto, resultado de la suma de 
nuestro espacio y del espacio de los demás, es el mundo, el lugar en el que debería contemplarse todo tipo de obras culturales como manifestaciones de la experiencia histórica de la Humanidad.

Es un hecho que la mirada que sobre la cultura tiene una institución de alcance mundial como la UNESCO está contaminada de eurocentrismo y occidentalismo (en 2012, de los 962 sitios reconocidos como patrimonio de la humanidad, prácticamente la mitad, el 48\%, se encuentran en Europa y América del Norte; el 52\% restante se lo reparten, según distribución de la propia institución, las otras cuatro áreas del planeta: África, Estados Árabes, Asia-Pacífico y América Latina y el Caribe); al mismo tiempo, es evidente que hoy lo cultural no puede verse al margen de lo socioeconómico. La UNESCO -empecinada durante años en diferenciar tajantemente entre el arte, el patrimonio, la actividad cultural, la industria del ocio y el turismo y los medios de comunicación social- se está encontrando con serias dificultades a la hora de establecer su programa patrimonial de la humanidad al margen de determinados factores políticos, religiosos, turísticos o mediáticos, factores que implican unas considerables consecuencias económicas. En diciembre de 2001, la Conferencia General de la UNESCO aprobó por unanimidad una Declaración universal sobre la diversidad cultural, un documento irrelevante si no se acompaña de una convención amparada por el derecho internacional que reconozca la singularidad de los diferentes bienes y servicios culturales y su necesaria protección. En la Conferencia General de otoño de 2005 se debatió y votó esa convención, que contó con partidarios (liderados por Francia) y detractores (con Estados Unidos a la cabeza, país que importa solo el $2 \%$ de su consumo cultural; el $90 \%$ de la producción editorial de ese país es de origen autóctono, el $7 \%$ procede de otros países de lengua inglesa y solo el 3\% restante corresponde a autores no anglófonos). Esta convención alude a una cooperación con los países del Sur y su aprobación supondría, entre otras cosas, poner en tela de juicio el predominio del derecho comercial sobre los demás derechos, cuestionar el librecambio salvaje que hace de esas instituciones inmunes a cualquier clase de control político que son la Organización Mundial del Comercio, el Fondo Monetario Internacional, la Organización de Cooperación y Desarrollo Económico, el Banco Mundial y el Banco Central Europeo los impulsores y principales garantes de la globalización liberal y, en ese mismo sentido, reivindicar la identidad cultural como un proceso colectivo basado en la memoria, la tradición y la experiencia, un proceso que responde a causas políticas e históricas determinadas (convendría recordar a este respecto que los países hoy más decididamente libre-cambistas - con Estados Unidos y el Reino Unido a la cabeza - han construido su potencial económico en buena medida sobre un proteccionismo que ahora condenan, hecho que demuestra que la economía no es una disciplina homogénea articulada sobre bases inamovibles sino que se presenta como un escenario de intereses, tensiones y conflictos donde se enfrentan diferentes modelos teóricos).

Sin embargo, en un contexto internacional arrasado por el tsunami neoliberal, parece que la UNESCO ha hecho una vez más dejación de sus funciones en lo que respecta a la regulación del sistema informativo mundial al permitir que sean otras instituciones guiadas por intereses económicos, principalmente la Organización Mundial del Comercio y la Organización Mundial de la Propiedad 
Intelectual, las que adopten las decisiones relacionadas con la propiedad intelectual, la libertad de expresión, información y circulación de comunicaciones. Eso ha provocado, entre otras cosas, que el campo artístico se haya convertido en un mercado hacia el que han sido atraídas cuantiosas inversiones procedentes de diferentes ámbitos, todos ellos con un enorme potencial económico, que tratan así de blanquear una parte de sus ingresos (empresas comerciales, industria armamentística, informática, textil, negocios bancarios, petroleros, mafias, etc.). Todavía en 2005 la UNESCO se vio en la necesidad de constituir una comisión de expertos (antropólogos, historiadores del arte, sociólogos, filósofos y semiólogos) con la intención de precisar los conceptos de patrimonio universal y obras universales de valor excepcional. Más recientemente, en una reunión celebrada en mayo de 2013 en Hangzhou, Irina Bokova, directora general de la UNESCO, ha reconocido el potencial de la cultura como motor económico frente a la crisis y, en ese sentido, la industria cultural se presenta como un escenario estratégico prioritario en el diseño de políticas de desarrollo. A la vista de los hechos, es evidente que la institución encargada de regular el patrimonio cultural y velar por su conservación ha tenido que ir modificando sus argumentos conforme cambiaban las coordenadas de tiempo y espacio.

En este escenario, la economía capitalista no responde a bases científicas contrastadas sino a fundamentos ideológicos (el librecambio es uno de ellos) que con frecuencia no tienen ninguna consistencia real. Como ya en su momento señalara Karl Marx, el librecambio es la libertad del capital, la libertad que ejerce el capital para sojuzgar al trabajador y solo en el caso de que esa libertad comercial y de capitales impulse la transformación y el progreso social hacia un mundo más justo, solo en ese posible sentido revolucionario, se debería actuar a favor del librecambio. En estas circunstancias, la economía real no debería dejarse en manos de algunos iluminados y recuperarse urgentemente como materia de confrontación política.

Hablar, en este contexto, con la certeza de que nuestro discurso tendrá que convivir con otros discursos y de que el paisaje del mundo será resultado de sumar las diferentes miradas, un paisaje que tendrá que derivar necesariamente de la coexistencia y la colaboración de las diferentes sociedades y culturas y no de la exclusión y eliminación de unas por otras, todo ello como fruto de una tradición cosmopolita que en Occidente se remonta a los pensadores cínicos y estoicos de la Antigüedad griega y llega hasta Goethe, Marx, Nietzsche, Adorno o Habermas. Se trataría de recuperar un escenario político nuevo en el que confluyan los problemas que nos conciernen a todos y se puedan discutir las soluciones, un espacio, en suma, desde el que pueda proyectarse un futuro común y compartido de la humanidad. En este sentido, el legado ilustrado y cosmopolita sobre el que se asienta el proyecto moderno de construcción europea (a pesar de todas sus carencias y miserias) constituye un bagaje que no debiera desestimarse y, de este modo, además de una realidad económica, jurídica y administrativa, la Unión Europea debería avanzar hacia la construcción de un espacio político, social y cultural en el que todos sus ciudadanos - conscientes de la diversidad, riqueza y complejidad de ese mismo espaciodisfruten de los mismos derechos. 
Convendría de este modo recordar que la Europa moderna -heredera de aquel legado ilustradoreivindicó siempre la pluralidad como un valor positivo y ante un escenario plural la actitud más deseable -preferible incluso a la tolerancia, que supone jerarquización de valores, ideas o creencias, respeto pero sin aceptación o aprobación expresas- sería aquella en la que el sujeto se expone y se entrega sin prejuicios ni condiciones a desarrollar formas de coexistencia, aun a riesgo de naufragar en el océano de la colectividad; en todo caso, la tolerancia -que no ha de verse como el horizonte infranqueable- implica un paso adelante en la conquista de una sociedad más justa, libre e igualitaria que renuncia al uso de la violencia para resolver sus propios desacuerdos internos.

4. En estas condiciones, se hace necesario abordar las prácticas artísticas a la luz de una filosofía crítica de la cultura que sea capaz de orientarnos en ese complejo y a veces caótico panorama que dibuja el arte poshistórico, en el que -como podemos comprobar a menudo- todo puede ser posible, incluso el arte antiestético, y ello en un momento en que la teoría estética clasicista ya no puede ser reivindicada por ese arte poshistórico y vaciado en ocasiones de artisticidad tan extendido en la posmodernidad, un tiempo además en que los escenarios tradicionales de exhibición artística (museos, galerías y salas de exposiciones, auditorios, teatros, etc.) conviven con las calles y espacios públicos de las grandes ciudades del planeta, donde surge el denominado street art, una modalidad artística urbana que no tiene nada que ver con esos destrozos ocasionados en las paredes urbanas por descerebrados e ignorantes y que plantea al ciudadano una relación distinta con su entorno. En este contexto, la contrapublicidad es el objetivo de algunas de estas acciones, que utilizan las vallas publicitarias para ridiculizar o mostrar la perversidad de lo que en ellas se anuncia y, en acciones que podrían calificarse de «piratería publicitaria» (Klein, 2001), parodian y alteran por completo los mensajes, hasta el punto de subvertirlos y revelar su verdad desnuda y desprovista de cualquier paraíso publicitario. Al mismo tiempo, este tipo de conductas supone un ataque a la línea de flotación del capitalismo, que tiende a tratar a la gente de manera cada vez más agresiva como clientes o consumidores mientras que se desentiende de ella en cuanto colectivo trabajador.

Frente a la protección que otorgan los espacios cerrados, el arte callejero -en el que ocupan un lugar destacado los grafitos- supone la apertura de un debate sobre las políticas que han de regular la gestión de los espacios públicos, surge con vocación efímera, a la intemperie, amenazado por las inclemencias del tiempo (la lluvia, el viento, el exceso de luz solar, etc.), perseguido a menudo por la autoridad gubernativa, que lo criminaliza y ve en él un síntoma de crítica y desestabilización sociales; en este sentido, y en paralelo a este arte callejero, ha desempeñado un papel importante Reclaim The Streets, el movimiento político surgido en mayo de 1995 en Londres; en el fondo, un movimiento como este persigue la recuperación de los espacios públicos y su liberación del control comercial. Ante esta situación, las multinacionales y las grandes empresas y corporaciones financieras - pero no solo ellas, también las administraciones públicas metropolitanas- no han tardado en reaccionar y han intentado domesticar a estos artistas callejeros y emergentes con el propósito de ponerlos a trabajar 
para sus propios fines, unos artistas que -aunque su actividad principal se lleve a cabo en las calles y de manera casi siempre muy artesanal- conocen y utilizan la tecnología en forma de webs, redes sociales, medios de comunicación electrónicos y vídeos de presentación técnica y profesionalmente muy bien elaborados (son cada día más los gobiernos municipales que -ante la proliferación de grafitos en las paredes de sus ciudades- contratan a esos artistas y les encargan la decoración de esos espacios).

Las ciudades - por el hecho de ser muchas de ellas el destino de esos movimientos migratorios a los que más arriba he aludido- son buenos exponentes de esa cultura glocal entendida como la suma de elementos globales y locales. En las calles de las ciudades encontramos la confluencia de lo social, es decir, la emergencia difusa de las identidades, diferencias y conflictos que surgen en todo espacio público, permiten medir la pulsión real de la gente con determinadas experiencias artísticas y otorgan a esas relaciones un componente inevitablemente político; de paso, las ciudades son también el escenario de continuas tensiones culturales, políticas y sociales. La ciudad entendida no tanto como una construcción cuyos itinerarios conducen casi siempre a unos grandes centros comerciales (esta es la versión más extendida de la polis) sino como un territorio abierto en el que pueden darse infinitas posibilidades, derivas, encuentros y colaboraciones entre los diferentes colectivos culturales, políticos, religiosos y sociales y en el que la identidad es una categoría que entra en juego en cada acción, una categoría en construcción que ha de dar cuenta del complejo cuerpo social.

La cultura popular, en general, al surgir en un espacio caracterizado por la heterogeneidad, tiene en cuenta estos principios y cobra imagen en modos de representación interactivos, horizontales, dialógicos y participativos (la action painting de Jackson Pollock, la idea de «creación abierta» tal como la entendían Asger Jorn, Guy Debord y otros situacionistas, The Living Theatre de Judith Malina y Julian Beck y el Atelier de Poésie Ouverte de Carlos Edmundo de Ory son ejemplos de recuperación del legado crítico de la vanguardia en los que la participación colectiva es fundamental). Los lugares en los que emerge este tipo de cultura son radicalmente impuros y mestizos -abiertos y no cerrados, públicos y no privados, atravesados por diferentes corrientes- y sus valores no descansan tanto en la exclusión y la competencia como en la inclusión y la cooperación; lo popular se presenta así como huella o cicatriz de lo invisible, como una imagen de resistencia crítica que vela por la restauración de lo desaparecido. Ahora bien, mientras la cultura popular dibuja un escenario abierto, plural y heterogéneo, la cultura de masas tiende no solo a la anulación de las diferencias sino también a la colonización a partir de un imaginario cultural y político de carácter monológico. Es, por decirlo en pocas palabras, la diferencia que hay entre la cultura entendida como expresión de las personas o como imposición a las personas, la tensión que se produce entre el empeño de reivindicar la cultura popular y de dar voz a los colectivos socialmente marginados y el análisis de la cultura de masas como una construcción ideológica opresiva.

5. Así las cosas, habría que reconocer el hecho de que eso que denominamos identidad cultural se da en un escenario en el que la cultura funciona como una estrategia de identificación y autoafirmación, 
en situaciones en las que se expone -sin condiciones, aun a riesgo de perderse- como una marca reveladora de nuestra propia personalidad; en este sentido podría afirmarse que toda identidad surge a partir de una incertidumbre, emerge en un lugar amenazado por el miedo de su propia desaparición y ese miedo -como tantas veces la historia nos ha mostrado- puede convertirse en la llave de paso de una política identitaria expansionista y aniquiladora del otro. Repensar, a la luz de los cambios históricos y tecnológicos de nuestro tiempo, sobre este nuevo escenario transnacional, la a menudo tensa convivencia entre los centros y las periferias, entre nosotros y los otros -aborígenes y extranjeros, categorías en cualquier caso intercambiables dependiendo del lugar en que se presenten-, en un momento de continuos flujos migratorios.

Por ello, porque la cultura implica una lucha contra la uniformidad, es conveniente aceptar que la identidad puede ser un requisito para el reconocimiento de las diferencias culturales pero nunca una excusa para legitimar prácticas basadas en la desigualdad, más aún si consideramos que toda identidad es mestiza y a veces ambivalente como muy bien muestra en un simple juego gramatical el pronombre personal nosotros, resultado de la confluencia de lo propio y lo ajeno: «También el reconocimiento de las diferencias -el reconocimiento mutuo del otro dentro de su carácter diferente- puede convertirse en característica de una identidad común» (Habermas, 2008: 50). Solo por ahí se puede superar el horizonte de una mirada limitada por la cerrazón intrafronteriza nacional y occidental, solo por ahí se puede ir hacia la descripción de fenómenos, acciones, generaciones o movimientos transnacionales, globales. Así, una vez abierta la grieta de la disparidad cultural, puede avanzarse hacia el reconocimiento de una metáfora comprehensiva de la otredad entendida como esa parte que ha de completarnos, una otredad que revele tanto los efectos de la diferencia como las condiciones que pueden hacer posible el reconocimiento del otro y, finalmente, el entendimiento mutuo.

\section{Referencias bibliográficas}

Bounan, Michel (2007): La loca historia del mundo. Trad. J. Lionetti. Barcelona, Melusina.

Debord, Guy (2000): La sociedad del espectáculo. Pról., trad. y notas J. L. Pardo. Valencia, PreTextos.

HABERMAS, Jürgen (2008): El derecho internacional en la transición hacia un escenario posnacional. Trad. D. Gamper. Madrid, Katz editores y CCCB.

KLEIN, Naomi (2001): No Logo. El poder de las marcas. Trad. A. Jockl. Barcelona, Paidós.

SALDAÑA, Alfredo (2011): «Sobre la construcción de la identidad en las prácticas culturales», Quaderns de Filologia. Estudis Literaris, XVI, 23-42.

- (2013): La huella en el margen. Literatura y pensamiento crítico, Zaragoza, Mira Editores. 